Totogetas

a

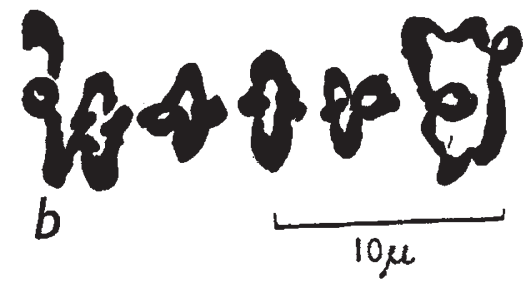

Meistic chromosomes in Extra Rapid translocation crossed (a) standard, (b) K line

of the slides. Fig. (a) shows the meiotic chromosome eomplement in the hybrid between the Extra Rapid translocation and the standard line, and Fig. (b) shows that of the $K$ line crossed the Extra Rapid translocation. Two associations of four and three bivalents are clearly seen.

The accompanying table gives further results of crosses involving the Extra Rapid translocation. These indicate that chromosomes 3 and 5 are in. volved, as in my original communication.

Results of crossing Extra Rapid translocation

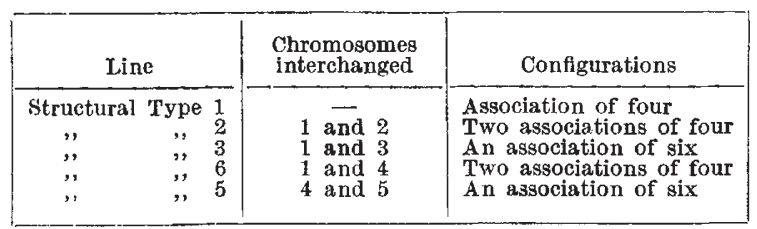

From correspondence with Dr. Lamm, I learn that the two translocations in the Extra Rapid variety arose independently. Therefore, it would seem that two different translocations are involved.

The genetical evidence of $\mathrm{Lamm}^{2}$ indicates that $G P$ on chromosome 2 is involved, and that of Nilsson ${ }^{3}$ suggests linkage with $B$ St on chromosome 3 , which would indicate that the Swedish Extra Rapid translocation involves chromos mes 2 and 3 . The two Extra Rapid translocations, if crossed, should give an association of six since they have chromosome 3 in common.

University College,

Eva Sansome

Ibadan, Nigeria. May 17.

I Sansome, E., Nature, 139, 113 (1937).

' Lamm, R., Hereditas, 35, 203 (1949).

s Nilsson, E., Hereditas, 36, 75 (1950).

\section{An Archiannelid from South Africa}

Several specimens of an Archiannelid were recently found on portions of the thallus of the prostrate alga, Codium Stephensice Dickinson, which had been kept in an aquarium for some months. They were also found to be abundant among the débris on the bottom of the tank. The Codium had been collected at Kommetjie on the Cape Peninsula, some twenty-two miles south of Cape Town.
The little worms are members of the genus Dinophilus Schmidt. Members of this genus fall into two groups : the species of one group are usually coloured, opaque and sexually monomorphic; the species of the other are usually colourless, transparent and sexually dimorphic. The South African specimens fall into the second group. The adult females are about 1-1.5 mm. long, and their appearance is very similar to the descriptions of Dinophilus gyrociliatus Schmidt, as given by Shearer ${ }^{1}$ and Fauvel $^{2}$, and they differ only in the presence of an extra segment (if the portion between constrictions constitutes a segment), and in the absence of any definite circum-anal ciliary band. The males are rudimentary and never leave the egg cocoon, where as soon as they become free from the egg membrane they were seen to copulate with the young females.

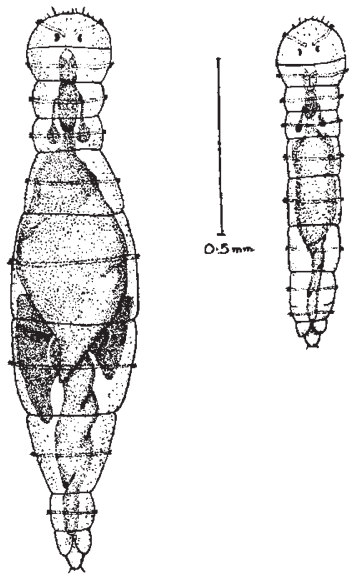
Adult (Ieft) and juvenile (right) female of Dinophilus gyrociliatus

Considering that Fauvel ${ }^{2}$ unites with $D$. gyrociliatus several species formerly separated by slight differences, the points of difference shown by these South African specimens do not seem to be sufficient to justify the making of a new species to include them, in spite of the fact that they have been found so far from the known range of $D$. gyrociliatus. Since these differences were found to be constant in some hundreds of specimens examined, they may be suffi. cient to constitute a new variety, and this will be proposed in a paper giving a full description of the specimens, to be published later.

So far as I can ascertain from the literature at my disposal, this is the first record of an Archiannelid not only from South Africa but also from the southern hemisphere.

My thanks are due to Prof. J. H. Day, of Cape Town, for confirmation of my identification, and to Miss P. L. Smuts, of the Department of Botany, University of Cape Town, for identifying the species of Codium on which the animals must have been introduced into the aquarium.

WM. Macnae

Department of Zoology,

University College,

Grahamstown,

South Africa.

${ }^{1}$ Shearer, C., Quart. J. Micr. Sci., 57 (1912). "Fauvel, P., "Faune de France: Polychaetes sédentaires" (Paris
1927 ). 